\title{
VALIDATING RANKINGS IN SOCCER CHAMPIONSHIPS
}

\author{
Annibal Parracho Sant'Anna* and \\ João Carlos Correia Baptista Soares de Mello
}

Received April 14, 2010 / Accepted September 5, 2011

\begin{abstract}
The final ranking of a championship is determined by quality attributes combined with other factors which should be filtered out of any decision on relegation or draft for upper level tournaments. Factors like referees' mistakes and difficulty of certain matches due to its accidental importance to the opponents should have their influence reduced. This work tests approaches to combine classification rules considering the imprecision of the number of points as a measure of quality and of the variables that provide reliable explanation for it. Two home-advantage variables are tested and shown to be apt to enter as explanatory variables. Independence between the criteria is checked against the hypothesis of maximal correlation. The importance of factors and of composition rules is evaluated on the basis of correlation between rank vectors, number of classes and number of clubs in tail classes. Data from five years of the Brazilian Soccer Championship are analyzed.
\end{abstract}

Keywords: soccer, performance management, probability.

\section{INTRODUCTION}

In 2006, the Brazilian Football Confederation (CBF) inaugurated a new structure for Brazilian football championships with the two highest leagues ( $1^{\text {st }}$ and $2^{\text {nd }}$ division $)$ with 20 teams playing against each other in a double robin format with 3 points per win and one per draw. The four teams with the lowest number of points in each division are relegated. The four with the highest number of points in the $2^{\text {nd }}$ division are promoted to the $1^{\text {st }}$, while the four with the highest number of points in the $1^{\text {st }}$ are selected to play Americas's Liberators Cup, the Latin American equivalent to the Champions Cup of Europe. This model, copied from European countries, intended to emphasize technical criteria and to stimulate offensive tactics, making the games more interesting and bringing more attendance to the soccer fields.

The practice did not accomplish the intentions of this move. In 2010 the average attendance per game was well below 15000 in the $1^{\text {st }}$ division and around 5000 in the $2^{\text {nd }}$ against an average

${ }^{*}$ Corresponding author

Departamento de Engenharia de Produção, Universidade Federal Fluminense - UFF, Rio de Janeiro, RJ, Brazil. E-mails: annibal.parracho@gmail.com / jcsmello@producao.uff.br 
around 17000 and 7000 in the preceding years. The number of goals scored declined. Experts link that to disillusion of fans with clearly unfair relegation of important clubs. The rule of three points per win makes the final round decisive for relegation and promotion for many clubs, while the lack of motivation of opponents by then away from that dispute brings abnormal results, suspects of bribing and violent protests.

The effects of the three-points-per-win rule were studied already, for instance, by Palacios-Huerta (2004) and Bloyce \& Murphy (2008). It is supposed to induce more offensive moves when the game is drawn, but what has been observed is that it inhibits the offensive posture of the team that scores first or gets a one goal lead along the game. Its evident flaw is that it assigns different weights to matches that finish with or without a winner.

Passion for soccer in Brazil developed along the twentieth century with limited influence of social factors like disputes between cities. There was a rivalry between the neighbour states of Rio de Janeiro, where was located the country capital for the largest part of the century and São Paulo, with the economic hegemony in the country long before it was accomplished the move of the capital to Brasilia, in the hinterland. During the decades of 50 and 60 the unique inter-states tournament involved only clubs of the states of Rio de Janeiro and São Paulo. In the other states there was frequently a double preference for a time of Rio de Janeiro or São Paulo and a local team, the national sympathy prevailing over the local preference. A National championship only started to happen by the end of the 60's. After that, in each state there remains some emulation between a small number of local clubs, usually two, and in matches between the team preferred in a national view and another antagonized in local grounds, the fan would strongly favour the team out of the state. This results in a culture where fidelity to the club plays an important role.

The Board ruling Soccer maintains, against a trend observed in other sports, that soccer rules are simple enough to be applied by a monocratic referee without any technical help to revise controversial decisions. For youngsters, seeing their preferred team presenting good performances and being unfairly evaluated is a motive for upheaval. Field game invasion and stadium plunder followed the relegation of Coritiba in 2009. This is not a general rule, since, for instance, Santa Cruz, a club that suffered successive relegations, although strongly complaining of referees' malicious decisions, keeps driving large and well-behaved crowds to support it. Recently, even relegated to the $4^{\text {th }}$ national division, it won the Pernambuco state championship with national records of attendance. But if injustice could be avoided, it would certainly help to raise moral standards.

Sant'Anna (2008) developed probabilistic procedures to derive alternative distributions into ordered classes that would avoid the anticipation of promotion and of relegation. In this approach, small differences in the official number of points contradicted by the performance according to other criteria are erased. On the other hand, a parallel classification may be applied to untie clubs with the same number of points earned.

These probabilistic procedures are set on a framework similar to that of Rough Sets Theory (Pawlak, 1982), with the relations applied divided into two parts, one formed by decision relations producing the official classification, and another, by condition relations, employed to challenge that classification on technical grounds. 
These relations need neither be transitive nor complete. They are set in terms of probabilities of preference between pairs. From these pairwise comparisons are derived probabilities of global preference according to the decision relations and according to the condition relations and the granularity of the classes is derived from the roughness in the measurement of such global preferences.

The inconsistencies between the two classifications give rise to a revision of the basic one, produced by sectioning or aggregating its classes. Aggregation is produced by erasing contradictions: if ' $\mathrm{X}$ ' is preferred to ' $\mathrm{Y}$ ' according to one of the classifications and ' $\mathrm{Y}$ ' is preferred to ' $\mathrm{X}$ ' according to the other, then a draw between ' $\mathrm{X}$ ' and ' $\mathrm{Y}$ ' is established. Sectioning occurs because, if elements ' $\mathrm{X}$ ' and ' $\mathrm{Y}$ ' are in the same class in one of the classifications, but ' $\mathrm{X}$ ' is preferred to ' $\mathrm{Y}$ ' according to the other, this last preference prevails.

There must be some coherence between the decision and condition relations. If they are highly contradictory, the final classes will be too large. On the other hand, if they are highly coincident the procedure will not reach its goal of improving the initial classification by increasing indiscernibility when needed.

A set of alternative classification rules to assure clearer cut points in the official ranking was studied by Sant'Anna et al. (2010), to the championships of 2006 and 2007. These rules combined three explanatory variables: number of goals scored by the team, number of goals taken and the balance of goals in the two games against each opponent. More consistent results are derived here from the analysis of a period of five years.

The preceding study did not take into account the phenomenon of "home advantage". The importance of this element has been stressed in a large set of studies (Courneya \& Carron, 1992; Balmer et al., 2001, 2003; Thomas et al., 2004; Jacklin, 2005; Pollard, 2006; Lacerda \& Soares de Mello, 2007; Lewis et al., 2007; Page \& Page, 2007). The existence of two turns in a long championship is not enough to deal with the distortions due to it, as in the second turn the games become more decisive. Just one error of the referee under pressure of the stands may result in a decisive difference of points. The contribution of the referees for the home advantage is studied, for instance, by Nevill et al. (2002), Groot (2005), Boyko et al. (2007), Dawson et al. (2007) and Downward \& Jones (2007).

The balance in direct confrontation helps taking this last feature into account as playing at home may affect differently games, for instance, against more popular or unpopular opponents, as observed by Leifer (1995), Madrigal \& James (1999) and Nevil et al. (2002). But this is only one of many possible effects of playing at home.

Other factors affecting the results of soccer games are suggested in the literature (Carmichael et al., 2000; Hofmann et al., 2002; Haas, 2003; Barros \& Leach, 2006; Caloba \& Lins, 2006; Goddard, 2006; Gelade \& Dobson, 2007). Variables like number of wins and of losses, number of goals scored and taken playing at home and outbound, number of attack moves or time of ball possession during the games (Espitia-Escuer \& García-Cebrián, 2004), may enter the analysis, whether on a total or on an individual basis. More explanatory factors may be employed as 
condition relations if a more precise representation is required. The criteria composition must be formulated then in such a way as preventing that the increase in the number of explanatory factors reduce excessively the number of resulting classes.

Here, classifications rules that take into account, besides the three factors considered in Sant'Anna et al. (2010), one more variable related to home advantage are studied here. Two new factors are considered separately: the presence of less games with home advantage for clubs of states with a larger number of clubs in the championship and the quality of the team playing away, measured by the balance of goals scored and taken in such games.

Different forms of composition were extensively compared in Sant'Anna et al. (2010). The composition algorithms here employed are those that produced the best fit to the number of points in those analyses. They take, as scores for the joint ranking, probabilities of simultaneous preference according to the whole set of criteria. This composition approach is in accordance with the idea that in Sports, excellence under every criterion must be required.

The composition rules proposed for promotion are different of those proposed for relegation. For promotion, the alternative classification is derived from the probability of being the best according to every criterion. For relegation, is tried, instead, the probability of not being the worst, again according to all the criteria.

Two different forms of computation of these probabilities are employed. The first assumes independence between the disturbances affecting the score of each club on each factor. The second preserves the independence between different teams but the scores of the same team according to different criteria are assumed to present maximal correlation.

The next section describes the probabilistic composition rules applied. Peculiarities of the application of the probabilistic approach to the classification of teams in a championship are discussed in Section 3. An introductory example of its application is described in Section 4. The inclusion of the explanatory variable measuring home advantage is more deeply discussed in Section 5. Changes in the results due to taking correlation into account in the criteria composition procedure are examined in Section 6. Section 7 presents general conclusions.

\section{PROBABILISTIC CRITERIA COMPOSITION}

A probabilistic approach is here applied to combine the condition relations into a unique score that allows for completely ranking the clubs. A detailed discussion of alternative approaches to derive probabilistic scores may be found in Sant'Anna (2002) and its application to the ranking of the clubs in a championship is discussed in Sant'Anna (2008) and Sant'Anna et al. (2010). The different composition rules presented similar results in this last study with slightly better results when rules involving the probabilities of maximizing or minimizing the preference according to all the criteria together were applied. This section is then limited to the description of this last set of rules. 
In the first composition procedures here studied, designed to assist on the cuts at the top of the Standings, the probabilistic composition employs as the global preference score the probability of being the best according to all the criteria. That means, the score of each team is the probability of, when compared to every opponent, beating it under every criterion. Assuming independence, this probability is the product of the probabilities of beating each opponent according to each criterion.

The other composition, designed to assist on relegation decisions, considers the inverted preferences. The global score combines the probabilities of not being beaten by all the opponents according to all the criteria. It is given, assuming independence, by the rest to 1 of the product, along the set of all opponents, of the probabilities of being beaten according to each criterion.

An assumption of positive correlation between the criteria may be more reasonable than that of independence. In fact, good offensive and defensive abilities help each other. Besides, the performance along the whole championship is related to the performance against each opponent. Simpler measures may be derived if we assume that these correlations are as high as possible. In that case, the product of probabilities according to each criterion must be replaced by the minimum of the factors of such product. This is so by the simple reason that the probability of joint occurrence of two events cannot be larger than the probability of each of them isolated. It will be verified in the development of this study that employing the product, instead of the minimum, increases the explanatory power of the alternative classification.

Before combining the criteria, the distribution of probabilities of preference according to each criterion must be determined. To estimate these probabilities, Sant'Anna et al. (2010) proposed a Pareto law, relating to the positive value $z$ of the difference between teams $X$ and $Y$ the probability $p_{Y X}(z)=1 /(z+1) /(z+2)$ of preference of $Y$ over $X$ and the probability $p_{X Y}(z)=1-p_{Y X}(z)$ of preference of $X$ over $Y$. In the case of a draw, that means, of $z=0$, the probability is $p_{X Y}(0)=p_{Y X}(0)=1 / 2$.

With that, the composition will assign less importance to direct confrontation balances, which present, naturally, smaller values than the comparisons by the sums of goals in all matches. This suitably reflects, without the need of assigning weights to the criteria, the fact that the total values provide more stable information. On the same way, for the variables related to home advantage, the variable indicating the number of games with home advantage will be given less importance than the balance of goals away from home.

\section{STRATEGIES FOR JOINT EVALUATION OF THE TEAMS}

The forms of composition above described are here employed to classify the teams by the end of Brazilian soccer championships. The main goal of the analysis is offering classifications that might be joined to that derived from the official counting of points to determine classes for relegation or promotion. The idea of employing a secondary classification to validate cut points of a basic classification is in the origin of Rough Sets Theory (Pawlak, 1982). The extension of this idea to the case of variables producing order relations is discussed in Greco et al. (1999). 
The basic idea is that of placing any club that is ranked above another in one of the two classifications and not below it in the other in a class above it and placing in the same class clubs that are ranked in opposite orders in the two classifications.

The confirmation of the cutting points by alternative rules based on a set of relevant criteria reinforces the legitimacy of relegation and promotion decisions. The relegation of important clubs, like Corinthians in 2006, Atlético-MG in 2007, Vasco da Gama in 2008 and Coritiba in 2009 , all easily returning the next year to the $1^{\text {st }}$ division, was a source of hard questioning of the validity of soccer results. The menace of facing surprising relegations like those is considered an important cause of loss of interest in the championship.

The use of a rule that employs different factors in alternative classifications helps to avoid anticipation of ranks that would result in loss of motivation for some clubs in the final rounds distorting the final outcome. Besides, when the technical alternative classification contradicts the official classification this may be an indication of extra-field influences affecting the results of the games of some teams.

Along the five years, the application of the alternative classification separates small classes at the upper and lower extremes of the ranking. Specially, the champion and the last ranked usually form a unitary class. Only in 2009, it is found the ranking based on the variables alternatively measuring the quality of the teams in strong disagreement to the ranking based on points earned from wins and draws. Two clubs, Flamengo and Fluminense, developed strong drives along the last weeks of the championship. The first is traditionally known as able to, driven by the enthusiasm of its huge crowd of supporters, overcome its limitations when there is a chance of being the champion, what finally happened, and the second was motivated by the possibility of escaping relegation after a pretty bad first half of the championship. On the other side, Palmeiras, who had been leading the Standings most of the time, scored only eight points along the last ten games when it faced opponents highly motivated, two of them being precisely Flamengo and Fluminense.

\section{THE ALTERNATIVE CLASSIFICATIONS}

Different classifications to confront the official ranking by points are here considered. All of them include, as explanatory variables, the number of goals scored and taken and the balance of direct confrontations. Compositions with a fourth variable related to home advantage are also considered. This fourth variable may be an indicator of the presence of local opponents or the balance of goals as a visitor. The effect of addition of these variables will be compared in the next section. In the present section, only the balance of goals as a visitor will be added.

Two composition approaches are taken: the promotion composition, by the probability of being the best according to all the explanatory variables, or the relegation composition, by the probability of not being the worst according to all these variables.

To concretely exemplify, Table 1 presents the final official total of points of the teams in the $1^{\text {st }}$ division of the championship of 2010 , as well as their ranks according to the above referred 
Table 1 - 2010 rankings for different composition rules.

\begin{tabular}{|l|c|c|c|c|c|c|c|c|}
\hline \multirow{2}{*}{ Team } & \multicolumn{2}{|c|}{3 factors } & \multicolumn{2}{c|}{ 4 factors } & $\begin{array}{c}\text { final- } \\
\text { promotion/ } \\
\text { relegation }\end{array}$ \\
\cline { 2 - 10 } & points & promotion & $\begin{array}{c}\text { final- } \\
\text { promotion }\end{array}$ & relegation & $\begin{array}{c}\text { final- } \\
\text { relegation }\end{array}$ & promotion & relegation & \\
\hline Fluminense/RJ & 1 & 1 & 1 & 1 & 1 & 1 & 1 & 1 \\
\hline Cruzeiro/MG & 2 & 4 & 3 & 4 & 3 & 4 & 4 & 3 \\
\hline Corinthians/SP & 3 & 2 & 3 & 2 & 3 & 3 & 3 & 3 \\
\hline Grêmio/RS & 4 & 3 & 3 & 3 & 3 & 2 & 2 & 3 \\
\hline Atlético/PR & 5 & 11 & 8 & 10 & 7.5 & 11 & 11 & 11.5 \\
\hline Botafogo/RJ & 6 & 5 & 8 & 6 & 7.5 & 5 & 5 & 11.5 \\
\hline Internacional/RS & 7 & 6 & 8 & 7 & 7.5 & 6 & 7 & 11.5 \\
\hline Santos/SP & 8 & 7 & 8 & 5 & 7.5 & 7 & 6 & 11.5 \\
\hline São Paulo/SP & 9 & 10 & 8 & 8 & 7.5 & 9 & 8 & 11.5 \\
\hline Palmeiras/SP & 10 & 8 & 8 & 9 & 7.5 & 8 & 9 & 11.5 \\
\hline Vasco/RJ & 11 & 9 & 8 & 11 & 11 & 12 & 14 & 11.5 \\
\hline Ceará/CE & 12 & 15 & 14.5 & 17 & 14.5 & 15 & 16 & 11.5 \\
\hline Atlético/MG & 13 & 17 & 14.5 & 14 & 14.5 & 16 & 15 & 11.5 \\
\hline Flamengo/RJ & 14 & 12 & 14.5 & 13 & 14.5 & 10 & 10 & 11.5 \\
\hline Avaí/SC & 15 & 16 & 14.5 & 15 & 14.5 & 17 & 17 & 11.5 \\
\hline Atlético/GO & 16.5 & 14 & 14.5 & 12 & 14.5 & 14 & 12 & 11.5 \\
\hline Vitória/BA & 16.5 & 13 & 14.5 & 16 & 14.5 & 13 & 13 & 11.5 \\
\hline Guarani/SP & 18 & 18 & 18 & 18 & 18 & 18 & 18 & 18 \\
\hline Goiás/GO & 19 & 20 & 19.5 & 19 & 19 & 19 & 19 & 19 \\
\hline Prudente/SP & 20 & 19 & 19.5 & 20 & 20 & 20 & 20 & 20 \\
\hline
\end{tabular}

strategies of composition of the explanatory factors assuming independence and the ranks of the classes they come to belong after the aggregating and sectioning procedures are applied.

The columns of Table 1 headed by the word promotion present the ranks of the clubs when their scores are calculated by multiplying the probabilities of beating every opponent according to each criterion. For the $k$-th club these probabilities are given by $1 /\left(z_{i j k}+1\right) /\left(z_{i j k}+2\right)$ where $z_{i j k}$ is the difference between the values for the $k$-th and $j$-th row in Table 2 for $i$ representing variables in that table and $z_{i j k}$ is the entry in the $k$-th row and $j$-th column of Table 3 for the case of $i$ representing direct confrontation. Conversely, rankings derived from the multiplications of the complements to 1 of these factors form the columns headed by the word relegation.

Those columns with the word final in the heading present the rankings generated by eliminating all contradictions between the respective promotion or relegation column and the second column, that with the ranking according to points earned.

When the fourth variable, balance away, is added, the final rankings are the same, whether assuming the promotion composition or the relegation composition. This final ranking is presented in the last column of Table 1.

The only strong contradiction in Table 1 is offered by Atlético-PR, who finished one win from classification among the four first, with a very small number of goals scored. A similar contradiction happened in the $1^{\text {st }}$ division in 2008 , offered by International, classified $6^{\text {th }}$ in the official 
Table 2 - 2010 Data of single variables.

\begin{tabular}{|l|c|c|c|c|}
\hline \multicolumn{1}{|c|}{ Club } & points & goals pro & goals against & Balance away \\
\hline Fluminense/RJ & 71 & 62 & 36 & 10 \\
Cruzeiro/MG & 69 & 53 & 38 & 3 \\
Corinthians/SP & 68 & 65 & 41 & -3 \\
Grêmio/RS & 63 & 68 & 43 & 4 \\
Atlético/PR & 60 & 43 & 45 & -13 \\
Botafogo/RJ & 59 & 54 & 42 & -1 \\
Internacional/RS & 58 & 48 & 41 & -3 \\
Santos/SP & 56 & 63 & 50 & -3 \\
São Paulo/SP & 55 & 54 & 54 & -4 \\
Palmeiras/SP & 50 & 42 & 43 & -4 \\
Vasco/RJ & 49 & 43 & 45 & -15 \\
Ceará/CE & 47 & 35 & 44 & -19 \\
Atlético/MG & 45 & 52 & 64 & -16 \\
Flamengo/RJ & 44 & 41 & 44 & -8 \\
Avaí/SC & 43 & 49 & 58 & -23 \\
Atlético/GO & 42 & 51 & 57 & -13 \\
Vitória/BA & 42 & 42 & 48 & -11 \\
Guarani/SP & 37 & 33 & 53 & -22 \\
Goiás/GO & 33 & 41 & 68 & -18 \\
Prudente/SP & 31 & 39 & 64 & -25 \\
\hline
\end{tabular}

Table 3 - 2010 Data for paired variable.

\begin{tabular}{|c|c|c|c|c|c|c|c|c|c|c|c|c|c|c|c|c|c|c|c|}
\hline & $\begin{array}{c}\mathrm{AT} / \\
\mathrm{MG}\end{array}$ & $\begin{array}{l}\text { AT/ } \\
\text { PR }\end{array}$ & $\begin{array}{l}\mathrm{AV} / \\
\mathrm{SC}\end{array}$ & $\begin{array}{l}\mathrm{BT} / \\
\mathrm{RJ}\end{array}$ & $\begin{array}{l}\mathrm{CE} / \\
\mathrm{CE}\end{array}$ & $\begin{array}{l}\mathrm{CR} / \\
\mathrm{SP}\end{array}$ & $\begin{array}{c}\mathrm{CZ} / \\
\mathrm{MG}\end{array}$ & $\begin{array}{c}\text { FM/ } \\
\text { RJ }\end{array}$ & $\begin{array}{l}\mathrm{FN} / \\
\mathrm{RJ}\end{array}$ & $\begin{array}{l}\mathrm{GO} / \\
\mathrm{GO}\end{array}$ & $\begin{array}{l}\text { GR/ } \\
\text { RS }\end{array}$ & $\begin{array}{c}\mathrm{GN} / \\
\mathrm{SP}\end{array}$ & $\begin{array}{l}\text { IN/ } \\
\text { RS }\end{array}$ & $\begin{array}{c}\mathrm{PM} / \\
\mathrm{SP}\end{array}$ & $\begin{array}{l}\mathrm{PR} / \\
\mathrm{SP}\end{array}$ & $\begin{array}{l}\mathrm{SN} / \\
\mathrm{SP}\end{array}$ & $\begin{array}{l}\mathrm{SP} / \\
\mathrm{SP}\end{array}$ & $\begin{array}{c}\mathrm{VC} / \\
\mathrm{RJ}\end{array}$ & $\begin{array}{l}\text { VT/ } \\
\text { BA }\end{array}$ \\
\hline $\mathrm{AT} / \mathrm{GO}$ & -2 & -2 & -3 & -3 & 0 & 3 & -2 & -3 & 0 & 0 & -2 & 1 & 0 & 6 & 2 & -3 & -1 & 0 & 3 \\
\hline $\mathrm{AT} / \mathrm{MG}$ & & 1 & 2 & -5 & -1 & 0 & 0 & 3 & -6 & 4 & -2 & 2 & -2 & 1 & -3 & -2 & -5 & 1 & -2 \\
\hline $\mathrm{AT} / \mathrm{PR}$ & & & 1 & 1 & -2 & 2 & -2 & -1 & 0 & -1 & 2 & -1 & -2 & 3 & -2 & -1 & 2 & -2 & 0 \\
\hline $\mathrm{AV} / \mathrm{SC}$ & & & & -1 & 3 & -3 & -1 & 0 & -4 & 2 & -6 & -2 & 0 & -1 & 5 & 0 & 1 & 2 & -3 \\
\hline $\mathrm{BT} / \mathrm{RJ}$ & & & & & 1 & 0 & -1 & -1 & 0 & 0 & -3 & 0 & -2 & 0 & 3 & 1 & 3 & 0 & 3 \\
\hline $\mathrm{CE} / \mathrm{CE}$ & & & & & & 0 & -1 & -1 & -1 & 0 & -3 & 2 & 0 & 0 & 0 & 1 & 1 & -4 & 1 \\
\hline $\mathrm{CR} / \mathrm{SP}$ & & & & & & & 0 & 1 & 2 & 4 & 0 & 2 & 1 & 1 & 3 & 3 & 5 & 0 & 1 \\
\hline $\mathrm{CZ} / \mathrm{MG}$ & & & & & & & & 2 & 0 & 2 & -1 & 2 & 2 & 2 & 2 & -3 & -2 & 2 & 0 \\
\hline $\mathrm{FM} / \mathrm{RJ}$ & & & & & & & & & -1 & -1 & 0 & 0 & 2 & -1 & 3 & 0 & -2 & 0 & 0 \\
\hline FN/RJ & & & & & & & & & & 3 & 3 & 0 & 3 & 1 & 0 & -2 & 3 & 1 & 2 \\
\hline $\mathrm{GO} / \mathrm{GO}$ & & & & & & & & & & & -4 & 1 & -1 & -1 & -4 & -5 & 4 & -1 & 1 \\
\hline GR/RS & & & & & & & & & & & & 4 & 0 & -3 & 2 & -1 & 0 & 0 & 3 \\
\hline $\mathrm{GN} / \mathrm{SP}$ & & & & & & & & & & & & & -6 & -1 & -1 & -2 & -1 & 2 & 0 \\
\hline IN/RS & & & & & & & & & & & & & & -2 & 5 & -1 & 0 & 0 & 0 \\
\hline $\mathrm{PM} / \mathrm{SP}$ & & & & & & & & & & & & & & & 1 & 1 & -3 & 0 & 1 \\
\hline $\mathrm{PR} / \mathrm{SP}$ & & & & & & & & & & & & & & & & 0 & -1 & -2 & -2 \\
\hline SN/SP & & & & & & & & & & & & & & & & & 0 & 2 & -2 \\
\hline SP/SP & & & & & & & & & & & & & & & & & & 0 & 1 \\
\hline $\mathrm{VC} / \mathrm{RJ}$ & & & & & & & & & & & & & & & & & & & -1 \\
\hline
\end{tabular}


standings and below the $10^{\text {th }}$ in most of the alternative classifications. On the opposite hand, clubs of Rio de Janeiro, like Fluminense and Vasco da Gama, present better ranks in the alternative classifications than in the classification by points. This seems to confirm a saying that the kind of soccer played by the clubs of the South is more driven to outcomes while the soccer played by the teams of Rio de Janeiro, even though more attractive for the spectators, is less appropriate to win the competitions.

Table 1 reveals that it is easy to separate the champion as well as the set of four clubs at the upper end in 2010. It is also easy to separate three clubs at the lower end. In the other years, except in 2009 , it was easy to separate one team at the upper end, i.e., the champion, and another as the last in line, at the lower end. Cuts at inner points are more difficult to determine.

Noticeable in Table 1 is also that the only tie in number of points in 2010 happened between Atlético-GO and Vitória, for the last relegation decision. Vitória, which would be ahead of Atlético-GO if the symmetric instead of the three-points-per-win counting were adopted, was relegated on the basis of an untying rule that overvalued once more the number of wins.

If the untying rule were based on attendance in hosted games, Vitória would stay in the $1^{\text {st }}$ division and Atlético-GO would be relegated. In fact, even though in a bad championship campaign, Vitória was ranked $12^{\text {th }}$ in attendance to the 2010 Brazilian championship, while Atlético-GO was the $17^{\text {th }}$, ahead only of the three other relegated clubs: Guarani was the $18^{\text {th }}$, Goiás the $19^{\text {th }}$ and Prudente the $20^{\text {th }}$, in attendance as well as in number of points won. The attendance criterion is in 2010 in good agreement with the points criterion. In Brazil, this criterion, if carefully applied, would award states of lower per capita income like Bahia, Ceará and Pernambuco the presence in the $1^{\text {st }}$ division of the Brazilian championship that has been sometimes denied and, technically, would do justice to the quality of the teams of these states.

Table 2 presents the points earned and the values of three explanatory variables: goals scored and suffered and balance away. Table 3 presents the balance of direct confrontations. The official rankings, as well as the values of the explanatory variables, were extracted from CBF (2010).

In these tables, it is possible to see general agreement to the total of points of the variables employed to compose the alternative classifications. It is also possible to detect visually discrepancies that show how this agreement is not complete. Let us consider, for instance, Ceará, with 47 points, ranked $12^{\text {th }}$ in the official classification, and Vitoria, with 42 , ranked $17^{\text {th }}$. In the balance of the two matches against each other, Ceará outscored Vitória by one goal. Besides, Ceará, in the total, suffered 3 less goals and scored one more goal at home. But Vitória scored abroad 8 more goals. The favourable balance of one goal results in a probability of Ceará being beaten by Vitória in the direct confrontation of 1/6. Multiplying the probabilities of being beaten in the 19 direct confrontations gives Ceará a probability of being beaten by the 19 opponents of $7 * 10^{-15}$, much lower than that of Vitoria, of $5 * 10^{-8}$. But the 42 goals scored, against the 35 goals scored by Ceará, make the product of the probabilities of being beaten, by all the three criteria: goals scored, goals taken and direct confrontation, smaller for Vitória than for Ceará, contradicting the official ranking and making the two clubs indiscernible. 


\section{THE EFFECT OF HOME ADVANTAGE}

Adding a fourth variable representing home advantage to those employed in Sant'Anna (2010) to derive the alternative classifications is here considered. Home advantage frequently decides soccer matches. Nevill et al. (1996) verified, comparing outcomes of matches of different divisions that the teams playing at home would more probably beat the visitors in those divisions with higher public interest.

By this reason, and because, along all the period considered, the Brazilian $2^{\text {nd }}$ division rarely had clubs of the same city, the analysis of home advantage is here limited to the $1^{\text {st }}$ division, where clubs of Rio de Janeiro, São Paulo, Minas Gerais and Goiás face the teams of the same state in a neutral field. The states of Paraná, Pernambuco and Rio Grande do Sul had also more than one team in the $1^{\text {st }}$ division each, but, there, each team plays in its own stadium and limits presence of opponent supporters to a small space, what allows to preserve some home advantage even against teams of the same city. So, the first variable created to represent home advantage was built assigning a handicap of two for the teams of that first set of states and a handicap of one for the teams of these last states.

A second proxy for home advantage was built with a smaller expected effect on changing the classification, but with a higher expected quality on evaluating the strength of the teams. It is given by the balance of goals in the games hosted by the opponent. i.e., the difference between the number of goals scored and the number of goals taken in all the games played on foreign grounds.

The addition of these variables had a small effect along the 5 years studied, as we will see in more detail when analysing the tables of the next section. This result shows that they can be employed in practice to improve the classification without excessively reducing the number of final classes. The addition of a fourth variable in the composition has generally the effect of mixing up the objects that we intend to separate, an effect that is expected to increase as the new variable has a smaller explanatory power.

In fact, adding, as a fourth explanatory variable, a variable measuring factors with a more indirect effect on the outcomes, such as popularity, measured by the number of spectators in the championship games of the clubs during the last years, or long range power of the teams, measured by their sum of points along the preceding championships, could not be recommended, as the number of classes generated became much smaller.

This applies also to variables that may be interesting to introduce by strategic reasons. For instance, to the offensive strength outbound measured by the number of goals scored away, which may be a good criterion to choose teams to play international tournaments, were the team plays abroad against strongly supported opponents. Or to the defensive ability in the games played at home, important when the interest is in selecting teams to international tournaments where goals scored in the opponent field are overvalued. 


\section{COMPARISON OF ALTERNATIVE ASSUMPTIONS}

In this section the results obtained for the different models under the assumption of independence between preferences according to the various criteria are compared to the results obtained under the assumption of dependence above discussed. The joint probabilities assuming such dependence between the distinct criteria are given by the minimum of the probabilities according to each criterion isolated, instead of the product. This leads to disregard in the computations part of the available numerical information, what, in previous analyses, resulted in smaller explanatory power relatively to the composition under independence, with the vectors of scores derived from independence presenting a higher correlation with the official classification. For this reason, we consider here only dependence between the criteria, not between the evaluations of different clubs by the same criterion. This limited dependence assumption leads to vectors of scores closer to those obtained by independence, with the same set of classes sometimes.

Tables 4, 5 and 6 reveal, by diverse features, the differences between classification approaches. They show clearly the best explanatory power obtained when independence is assumed and the final scores are given by the products of the evaluations according to the different criteria instead of the minima, but other differences can also be noticed. Table 4 presents the number of classes obtained after the alternative classification is combined with the official classification. Table 5 presents the number of teams in the lowest final class. Similar results are obtained for the number of teams in the front class. Table 6 presents the Spearman correlation between the initial and final classifications, i.e., the coefficients of correlation between the vectors of ranks obtained before and after applying the comparison between the official and the alternative classifications.

In all these tables, for each year, the values in the first row correspond to the classification with the balance of goals away included as a fourth explanatory variable for the results of the $1^{\text {st }}$ division and the second row corresponds to the handicap for games in neutral field included instead. The third and fourth rows correspond to the models with the three variables employed in Sant'Anna et al. (2010), respectively for the $1^{\text {st }}$ and the $2^{\text {nd }}$ division.

In Table 4, only four times the number of classes generated is larger when the hypothesis of correlation is applied, showing the advantage of employing the product of the probabilities of preference by each criterion. The differences from one row to the other are all small, showing that the inclusion of a variable to take into account home advantage will not reduce the number of cuts in an important manner. It can be noticed also that no systematic difference can be noticed between the results for the $1^{\text {st }}$ and the $2^{\text {nd }}$ division.

The analysis of Table 5 confirms the advantage of the use of products in the combination of the criteria. Employing this computation the number of clubs in the class never exceeds 4, what happens 4 times when the extreme value is employed. It is also confirmed the massive presence of only one team in the last class and no important effect of the inclusion of a fourth variable related to home advantage. The same occur for the first class. It can be pointed also that no systematic difference appears between the results for the $1^{\text {st }}$ and the $2^{\text {nd }}$ division. 
Table 4 - Number of classes.

\begin{tabular}{|c|c|c|c|c|}
\hline 2006 & $\begin{array}{c}\text { Product } \\
\text { promotion }\end{array}$ & relegation & $\begin{array}{c}\text { Extreme } \\
\text { promotion }\end{array}$ & relegation \\
\hline Balance away as $4^{\text {th }}$ factor & 6 & 6 & 4 & 3 \\
Neutral Field as $4^{\text {th }}$ factor & 6 & 6 & 4 & 5 \\
3 factors $-1^{\text {st }}$ division & 5 & 6 & 4 & 5 \\
3 factors $-2^{\text {nd }}$ division & 7 & 10 & 6 & 4 \\
\hline 2007 & & & & \\
\hline Balance away as $4^{\text {th }}$ factor & 5 & 5 & 5 & 5 \\
Neutral Field as $4^{\text {th }}$ factor & 7 & 7 & 4 & 4 \\
3 factors $-1^{\text {st }}$ division & 6 & 6 & 5 & 4 \\
3 factors $-2^{\text {nd }}$ division & 4 & 4 & 2 & 4 \\
\hline 2008 & & & & \\
\hline Balance away as $4^{\text {th }}$ factor & 9 & 5 & 6 & 6 \\
Neutral Field as $4^{\text {th }}$ factor & 6 & 6 & 6 & 7 \\
3 factors $-1^{\text {st }}$ division & 9 & 7 & 5 & 7 \\
3 factors $-2^{\text {nd }}$ division & 5 & 5 & 4 & 6 \\
\hline 2009 & & & & \\
\hline Balance away as $4^{\text {th }}$ factor & 6 & 6 & 5 & 5 \\
Neutral Field as $4^{\text {th }}$ factor & 4 & 4 & 2 & 4 \\
3 factors $-1^{\text {st }}$ division & 5 & 8 & 5 & 5 \\
3 factors $-2^{\text {nd }}$ division & 5 & 3 & 6 & 4 \\
\hline 2010 & & & & \\
\hline Balance away as $4^{\text {th }}$ factor & 6 & 6 & 6 & 3 \\
Neutral Field as $4^{\text {th }}$ factor & 5 & 6 & 3 & 4 \\
3 factors $-1^{\text {st }}$ division & 7 & 8 & & \\
\hline factors $-2^{\text {nd }}$ division & 5 & 8 & & \\
\hline
\end{tabular}

Analyzing Table 6 we can see once more the advantage of the multiplication procedure, with the two first columns of Spearman correlations presenting generally higher values. Inversions of this pattern are rare and most of them by small differences. Examining the correlations it can be detected the expected loss as the number of variables increases moving the alternative classification away from the initial one, but it is still a small difference that would not be enough to derail the practical use of the classification including the home advantage variables. The comparison of the two divisions shows only in 2008 a higher correlation for the results of the first division, indicating a greater homogeneity of the clubs in the $2^{\text {nd }}$ division or a smaller power of the variables chosen to explain the ranking of that year. 
Table 5 - Number of teams in the last final class.

\begin{tabular}{|c|c|c|c|c|}
\hline & $\begin{array}{c}\text { Product } \\
\text { promotion }\end{array}$ & relegation & $\begin{array}{l}\text { Extreme } \\
\text { promotion }\end{array}$ & relegation \\
\hline \multicolumn{5}{|l|}{2006} \\
\hline Balance away as $4^{\text {th }}$ factor & 1 & 1 & 1 & 1 \\
\hline Neutral Field as $4^{\text {th }}$ factor & 1 & 1 & 1 & 1 \\
\hline 3 factors $-1^{\text {st }}$ division & 1 & 1 & 1 & 1 \\
\hline 3 factors $-2^{\text {nd }}$ division & 1 & 1 & 9 & 2 \\
\hline \multicolumn{5}{|l|}{2007} \\
\hline Balance away as $4^{\text {th }}$ factor & 1 & 1 & 1 & 1 \\
\hline Neutral Field as $4^{\text {th }}$ factor & 1 & 1 & 1 & 1 \\
\hline 3 factors $-1^{\text {st }}$ division & 1 & 1 & 1 & 1 \\
\hline 3 factors $-2^{\text {nd }}$ division & 1 & 1 & 1 & 1 \\
\hline \multicolumn{5}{|l|}{2008} \\
\hline Balance away as $4^{\text {th }}$ factor & 1 & 1 & 1 & 1 \\
\hline Neutral Field as $4^{\text {th }}$ factor & 1 & 1 & 1 & 1 \\
\hline 3 factors $-1^{\text {st }}$ division & 1 & 1 & 1 & 1 \\
\hline 3 factors $-2^{\text {nd }}$ division & 1 & 1 & 17 & 1 \\
\hline \multicolumn{5}{|l|}{2009} \\
\hline Balance away as $4^{\text {th }}$ factor & 2 & 2 & 2 & 1 \\
\hline Neutral Field as $4^{\text {th }}$ factor & 4 & 4 & 6 & 1 \\
\hline 3 factors $-1^{\text {st }}$ division & 2 & 1 & 1 & 2 \\
\hline 3 factors $-2^{\text {nd }}$ division & 1 & 1 & 1 & 1 \\
\hline \multicolumn{5}{|l|}{2010} \\
\hline Balance away as $4^{\text {th }}$ factor & 1 & 1 & 1 & 1 \\
\hline Neutral Field as $4^{\text {th }}$ factor & 2 & 2 & 12 & 3 \\
\hline 3 factors $-1^{\text {st }}$ division & 2 & 1 & 2 & 3 \\
\hline 3 factors $-2^{\text {nd }}$ division & 1 & 1 & 1 & 1 \\
\hline
\end{tabular}

\section{FINAL COMMENTS}

Identification with clubs has an important role in behaviour in present times, mainly for younger generations. It has effects on the identity development of children (Erikson, 1968; Hughson et al., 2005). Thus the fair classification of the clubs is a matter of social concern.

The evidence here brought is in the direction to sustain that the number of points earned, in a count of three points by win and one by draw, may not even choose the best as the champion and the worst as the last ranked. At least for intermediary cuts, it has been made pretty clear that other variables should help the classification.

Besides, the variables here employed may have a real effect on stimulating the effort to raise the difference in goals scored at any match. Thus, instead of overvaluing the simple win, employing in a secondary classification variables based on the counting of goals scored and 
Table 6 - Correlation to the vector of points earned.

\begin{tabular}{|c|c|c|c|c|}
\hline & $\begin{array}{c}\text { Product } \\
\text { promotion }\end{array}$ & relegation & $\begin{array}{c}\text { Extreme } \\
\text { promotion }\end{array}$ & relegation \\
\hline \multicolumn{5}{|l|}{2006} \\
\hline Balance away as $4^{\text {th }}$ factor & 0.96 & 0.76 & 0.76 & 0.62 \\
\hline Neutral Field as $4^{\text {th }}$ factor & 0.96 & 0.96 & 0.76 & 0.85 \\
\hline 3 factors $-1^{\text {st }}$ division & 0.88 & 0.96 & 0.76 & 0.85 \\
\hline 3 factors $-2^{\text {nd }}$ division & 0.95 & 0.97 & 0.94 & 0.88 \\
\hline \multicolumn{5}{|l|}{2007} \\
\hline Balance away as $4^{\text {th }}$ factor & 0.70 & 0.70 & 0.71 & 0.71 \\
\hline Neutral Field as $4^{\text {th }}$ factor & 0.81 & 0.82 & 0.63 & 0.63 \\
\hline 3 factors $-1^{\text {st }}$ division & 0.85 & 0.82 & 0.71 & 0.63 \\
\hline 3 factors $-2^{\text {nd }}$ division & 0.86 & 0.86 & 0.88 & 0.71 \\
\hline Balance away as $4^{\text {th }}$ factor & 0.93 & 0.63 & 0.81 & 0.96 \\
\hline \multicolumn{5}{|l|}{2008} \\
\hline Balance away as $4^{\text {th }}$ factor & 0.93 & 0.63 & 0.81 & 0.96 \\
\hline Neutral Field as $4^{\text {th }}$ factor & 0.94 & 0.95 & 0.93 & 0.94 \\
\hline 3 factors $-1^{\text {st }}$ division & 0.96 & 0.97 & 0.92 & 0.97 \\
\hline 3 factors $-2^{\text {nd }}$ division & 0.76 & 0.76 & 0.62 & 0.85 \\
\hline \multicolumn{5}{|l|}{2009} \\
\hline Balance away as $4^{\text {th }}$ factor & 0.97 & 0.88 & 0.85 & 0.69 \\
\hline Neutral Field as $4^{\text {th }}$ factor & 0.81 & 0.81 & 0.80 & 0.69 \\
\hline 3 factors $-1^{\text {st }}$ division & 0.88 & 0.85 & 0.87 & 0.87 \\
\hline 3 factors $-2^{\text {nd }}$ division & 0.89 & 0.52 & 0.91 & 0.62 \\
\hline \multicolumn{5}{|l|}{2010} \\
\hline Balance away as $4^{\text {th }}$ factor & 0.85 & 0.85 & 0.85 & 0.52 \\
\hline Neutral Field as $4^{\text {th }}$ factor & 0.95 & 0.96 & 0.88 & 0.62 \\
\hline 3 factors $-1^{\text {st }}$ division & 0.97 & 0.97 & 0.81 & 0.93 \\
\hline 3 factors $-2^{\text {nd }}$ division & 0.87 & 0.91 & 0.93 & 0.88 \\
\hline
\end{tabular}

taken, attends the interest in stimulating offensive strategies. Composing these explanatory variables in an aggregate score helps to avoid manipulation and leads the interest for each club game till the last round.

The results obtained show that the validation of the classification by points by alternative classification rules taking into account multiple performance variables can be done. In particular, the influence of home advantage can be taken into account in different manners.

The use of the alternative rules would reduce the menace of unfair relegations and promotions if, for instance, coupled with complementary untying final procedures. Variables unrelated to the performances along the championship might be reserved to this function. Such variables might be, for instance, ranks based on the performance in previous years or on the public attendance to the games of the team along the championship. 


\section{ACKNOWLEDGMENTS}

We are grateful for the referees comments, that helped us to considerably improve the text, even though mistakes eventually remaining are no doubt of our entire responsibility. We are also thankful for the support provided by CAPES, CNPq and FAPERJ.

\section{REFERENCES}

[1] Balmer NJ, Nevill AM \& Williams AM. 2001. Home advantage in the Winter Olympics (1908-1998). Journal of Sports Sciences, 19(2): 129-139.

[2] Balmer NJ, Nevill AM \& Williams AM. 2003. Modelling home advantage in the Summer Olympic Games. Journal of Sports Sciences, 21(6): 469-478.

[3] Barros CP \& Leach S. 2006. Performance evaluation of the English premier football league with data envelopment analysis. Applied Economics, 38(12): 1449-1458.

[4] Bloyce D \& Murphy P. 2008. Sports administration on the hoof: The three points for a win "experiment" in English soccer. Soccer and Society, 9(1): 14-27.

[5] Воуко RH, Воуко AR \& Bоуко MG. 2007. Referee bias contributes to home advantage in English premiership football. Journal of Sports Sciences, 25(11): 1185-1194.

[6] Caloba GM \& Lins MPE. 2006. Performance assessment of the soccer teams in Brazil using DEA. Pesquisa Operacional, 26(3): 521-536.

[7] Carmichael F, Thomas D \& Ward R. 2000. Team performance: The case of English premiership football. Managerial and Decision Economics, 21(1): 31-45.

[8] CBF. 2010. Site of Brazilian Championships, http://www.cbf.com.br.

[9] COURNEYA KS \& CARRON AV. 1992. The home advantage in sport competitions: A literature review. Journal of Sport \& Exercise Psychology, 14(1): 13-27.

[10] Dawson P, Dobson S, Goddard J \& Wilson J. 2007. Are football referees really biased and inconsistent? Evidence on the incidence of disciplinary sanction in the English premier league. Journal of the Royal Statistical Society. Series A: Statistics in Society, 170(1): 231-250.

[11] Downward P \& Jones M. 2007. Effects of crowd size on referee decisions: Analysis of the FA cup. Journal of Sports Sciences, 25(14): 1541-1545.

[12] ERIKSON EH. 1968. Identity: Youth and crisis. New York: W.W. Norton.

[13] Espitia-Escuer M \& García-Cebrián LI. 2004. Measuring the efficiency of Spanish firstdivision soccer teams. Journal of Sports Economics, 5(4): 329-346.

[14] Gelade GA \& Dobson P. 2007. Predicting the comparative strengths of national football teams. Social Science Quarterly, 88(1): 244-258.

[15] Goddard J. 2006. Who wins the football? Significance, 3(1): 16-19.

[16] Greco S, Matarazzo B \& Slowinski R. 1999. Rough Approximation of a Preference Relation by Dominance Relations. European Journal of Operations Research, 19: 63-83.

[17] GROот L. 2005. Referees among most important players in soccer tournaments. Journal of Sport and Social Issues, 29(4): 437-442.

[18] HaAs DJ. 2003. Productive efficiency of English football teams - a data envelopment analysis approach. Managerial and Decision Economics, 24(5): 403-410. 
[19] Hofmann R, Ging LC \& Ramasamy B. 2002. The socio-economic determinants of international soccer performance. Journal of Applied Economics, 5(2): 253-272.

[20] Hughson J, Inglis D \& Free M. 2005. The uses of sports: A critical study. London: Routledge.

[21] JACKLIN PB. 2005. Temporal changes in home advantage in English football since the Second World War: What explains improved away performance? Journal of Sports Sciences, 23(7): 669-679.

[22] Lacerda FG \& Soares de Mello JCCB. 2007. Análise preliminar de existência de home advantage aplicada ao desempenho da República Dominicana na história dos jogos pan americanos. Relatórios de Pesquisa em Engenharia de Produção, 7(8).

[23] LeIfer EM. 1995. Perverse effects of social support: Publics and performance in major league sports. Social Forces, 74: 81-118.

[24] LEWIS HF, SEXTON TR \& Lock KA. 2007. Player salaries, organizational efficiency, and competitiveness in major league baseball. Journal of Sports Economics, 8(3): 266-294.

[25] Madrigal R \& James J. 1999. Team quality and the home advantage. Journal of Sport Behavior, 22: $381-398$.

[26] Nevill AM, Balmer NJ \& Williams AM. 2002. The influence of crowd noise and experience upon referring decisions in football. Psychology of Sport and Exercise, 3(4): 261-272.

[27] Nevill AM, Newell SM \& Gale S. 1996. Factors associated with home advantage in English and Scottish soccer matches. Journal of Sports Sciences, 14(2): 181-186.

[28] Page L \& Page K. 2007. The second leg home advantage: Evidence from European football cup competitions. Journal of Sports Sciences, 25(14): 1547-1556.

[29] Palacios Huerta I. 2004. Structural Changes During a Century of the World's Most Popular Sport. Statistical Methods and Applications, 13(2): 241-258.

[30] PawlaK Z. 1982. Rough Sets. International Journal of Computer and Information Sciences, 11: 341-356.

[31] POLlaRd R. 2006. Worldwide regional variations in home advantage in association football. Journal of Sports Sciences, 24(3): 231-240.

[32] Sant'Anna AP. 2002. Data Envelopment Analysis of randomized ranks. Pesquisa Operacional, 22(2): 203-215.

[33] Sant'Anna AP. 2008. Rough sets analysis with antisymmetric and intransitive attributes: Classification of Brazilian soccer clubs. Pesquisa Operacional, 28(2): 217-230.

[34] Sant'Anna AP, Uchoa E \& Soares de Mello JCCB. 2010. Classification of the teams in the Brazilian soccer championship by probabilistic criteria composition. Soccer and Society, 11(3): 261-276.

[35] Thomas S, Reeves C \& Davies S. 2004. An analysis of home advantage in the English football premiership. Perceptual and Motor Skills, 99(3 II): 1212-1216. 